
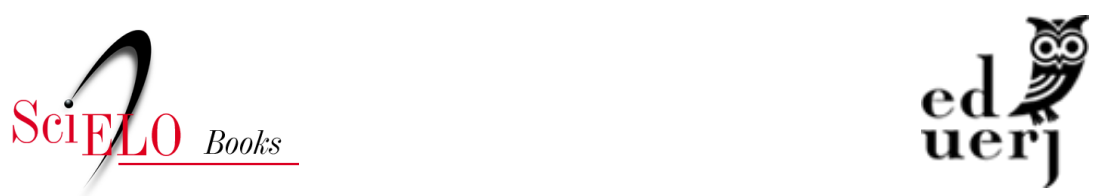

\title{
Capítulo 7 - Congresso remoto, pandemia e medidas em tempos de crise
}

\author{
João Feres Júnior
}

\section{SciELO Books / SciELO Livros / SciELO Libros}

FERES JÚNIOR, J. Congresso remoto, pandemia e medidas em tempos de crise. In.: SANTOS, F., ed. Congresso remoto: a experiência legislativa brasileira em tempos de pandemia [online]. Rio de Janeiro, 2021, pp. 115-128. Sociedade e política collection. ISBN: 978-65-88808-12-2.

https://doi.org/10.7476/9786588808122.0009.

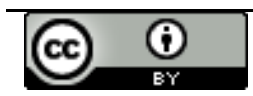

All the contents of this work, except where otherwise noted, is licensed under a Creative Commons Attribution 4.0 International license.

Todo o conteúdo deste trabalho, exceto quando houver ressalva, é publicado sob a licença Creative Commons Atribição 4.0.

Todo el contenido de esta obra, excepto donde se indique lo contrario, está bajo licencia de la licencia Creative Commons Reconocimento 4.0. 


\section{Capítulo 7 \\ Congresso Remoto, PANDEMIA E MEDIDAS EM TEMPOS DE CRISE}

João Feres Júnior

\section{Introdução}

Neste capítulo, abordaremos a iniciativa do Congresso Remoto sob a perspectiva de um contexto conceitual e histórico denso, a fim de capturarmos alguns de seus aspectos mais importantes no que toca a existência e funcionamento do regime democrático em nosso país. Partimos da observação óbvia de que tal iniciativa só se justifica devido à situação de crise instalada com o advento da pandemia. Em seguida, examinamos como situações de crise foram tratadas historicamente pelas instituições políticas do ocidente e pelo pensamento político, mais especificamente. Analisamos então as medidas de exceção preconizadas para tais situações críticas e sua evolução histórica. Também sumarizamos as medidas contidas na Constituição Federal para dar conta de tais situações. Por fim, examinamos o Congresso Remoto no contexto das relaçôes atuais entre Executivo e Legislativo, tendo como pano de fundo a história recente de nosso país. 


\section{Pandemia e crise}

Uma das palavras mais usadas para descrever as consequências da pandemia é "crise". Na verdade, fala-se de várias crises. Antes de mais nada a crise no sistema de saúde, mas também a crise na saúde de cada um que adoece por infecção do vírus; a crise na economia, mas também a crise individual dos milhões de pessoas afetadas economicamente pela pandemia; crise de abastecimento de produtos básicos; crise do sistema educacional devido à paralização de atividades presenciais; crise psicológica que aflige mesmo aqueles que não ficaram doentes... A lista das crises é por demais imensa para ser reproduzida nos limites deste ensaio.

Uma rápida busca por essa palavra em um dicionário da língua portuguesa revela o uso apropriado do termo para o caso atual da pandemia e mais alguma riqueza semântica. As definições apresentadas são:

Mudança brusca produzida no estado de um doente, causada pela luta entre o agente agressor e os mecanismos de defesa. Período de manifestação aguda de uma doença: crise de apendicite.

Manifestação violenta, repentina e breve de; acesso: crise epilética.

Conjuntura socioeconômica problemática, desequilíbrio entre bens de produção e de consumo, normalmente definida pelo aumento dos preços, pelo excesso de desemprego, de falências: crise econômica.

[Figurado] Momento perigoso ou difícil; período de desordem.

[Figurado] Situação conflituosa; tensão: crise familiar.

[Figurado] Expressão de ausência, carência: crise de mão de obra. Em que há decadência; queda: crise de moralidade. ${ }^{4}$

4 Disponível em: https://www.dicio.com.br/crise/. Consultado em 11 de janeiro de 2021. 
Como podemos constatar os significados do termo em nossa língua se reduzem basicamente aos de situação aguda e situação de conflito sem resolução, impasse. Contudo, esse exame rápido do verbete de dicionário não revela camadas semânticas hoje soterradas do conceito de crise, que podem auxiliar na presente reflexão.

Crise chegou ao português por meio do latim, que, por seu

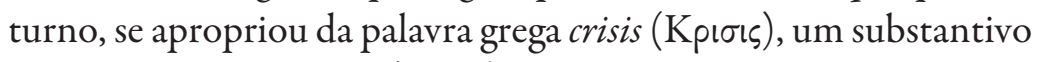
derivado do verbo krino ( $\mathrm{p} p v \omega)$, que no grego clássico tinha vários sentidos, entre eles separar, divorciar, julgar, decidir, discutir e brigar (Koselleck e Richter, 2006, p. 358). Ainda que os significados de tensão e contenda já estivessem presentes naquele contexto, havia também um outro que se perdeu, o de decisão ou julgamento. A conexão entre esses dois significados era o de que as coisas quando atingem um ponto "crítico" - palavra de mesma raiz - pedem uma decisão, uma solução. O sentido de julgamento era na verdade duplo, pois o termo poderia ser empregado em grego como crítica subjetiva ou como crise objetiva. Ao fazer a crítica de algo, estamos fazendo um julgamento. Por outro lado, uma crise objetiva é uma situação que demanda decisão (Koselleck e Richter, 2006, p. 360).

A palavra crise foi também apropriada pelo discurso jurídico, pelo discurso político, pela medicina e pela teologia do cristianismo primitivo, para falar do juízo (Kpıøı) final. No âmbito da doutrina religiosa uma nova possibilidade se incorpora ao campo semântico do conceito que só viria a se desenvolver plenamente dois milênios depois, com o Iluminismo na Europa e a Era das Revoluções. Esse desenvolvimento tem a ver com a mudança da concepção de historicidade embutida no conceito. Os gregos tinham várias narrativas de temporalidade, mas a dominante era a circular (Lovejoy e Boas, 1935), uma concepção ainda bastante lastreada no ritmo natural das estações, segundo o qual os seres nascem, se desenvolvem, alcançam a plenitude, decaem e morrem, para então renascerem e repetirem o ciclo. Tal ideia, tão facilmente associada aos efeitos do tempo sobre animais e vegetais, foi transplantada para outras áreas do conheci- 
mento, inclusive para a ciência política, como bem mostra Platão na República, com seu ciclo das formas de governo (Plato e Jowett, 2000). Assim, a decisão demandada pela crise na concepção clássica tinha por finalidade restaurar o objeto "criticado" à sua condição de plenitude, ou mesmo interromper ou retardar o processo de degeneração produzido pelo passar do tempo. $\mathrm{O}$ pensamento cristão, com sua noção de Juízo Final, introduz a inovação semântica de pensar a crise como o momento de passagem para uma nova época, ainda não experimentada. Não mais restaurativa, essa crise significa o fim de uma era e o começo de outra, radicalmente diferente. De Paulo a Voltaire, os cristãos mantiveram a crença no Juízo Final como esse advento imprevisível que marcaria o fim da história secular.

Para o cristianismo primitivo a "história" secular não tinha sentido frente à importância do advento eminente do retorno do messias, com o consequente julgamento final. Contudo, com o passar do tempo, e a não ocorrência de tal evento, o registro dos acontecimentos humanos passou a adquirir algum significado. É, contudo, bastante revelador notar que mesmo humanistas, como Maquiavel (1469-1527), que viveu mais de mil anos depois de Santo Agostinho (354-430) - autor que sustenta a clássica rejeição do cristianismo à história secular -, pensavam a história ainda pela ótica da exemplaridade, seguindo assim a fórmula dos grandes historiadores gregos e romanos. Foi na Era das Revoluções que se produziu a síntese entre a expectativa redentora da crise final, que anuncia a nova era, e uma concepção imanente de história humana. A revolução torna-se esse momento crítico, produto do desenvolvimento da história secular, no qual os homens escolhem abolir a situação anterior e lançam as bases de uma nova era, de uma nova sociedade. Em outras palavras, na ideia moderna de revolução os vários sentidos de "crise" se fundem a uma nova concepção de tempo histórico. 


\section{Soluções para a crise}

A solução para a crise, entendida mesmo em seu sentido clássico de conflito, foi questão fundadora da tradição do pensamento político ocidental. A República de Platão pode ser lida como projeto abrangente de uma pólis que resista às potenciais crises oriundas da vida coletiva - e fica claro que o autor é um tanto cético acerca da possibilidade de resistência absoluta à degeneração inexorável trazida pelo tempo (Plato e Jowett, 2000). Em termos atuais, a República fornece um desenho institucional, bastante aristocrático, para o problema da crise política inerente ao funcionamento da vida na pólis.

A Politica de Aristóteles contém inúmeros conselhos para se evitar os efeitos mais deletérios das crises sociais e políticas (Aristotle, 1996). Também em termos atuais, o autor fornece um catálogo de soluções possíveis para dar conta das várias configurações sociais e políticas que possam vir a causar uma crise política. Políbio, historiador grego radicado em Roma do século II a.C, é outro exemplo importante da preocupação central em propor um desenho institucional que resistisse às crises oriundas do processo de degeneração temporal ao qual todas as coisas estavam sujeitas (Pocock, 1975). Mesmo Maquiavel, escrevendo mais de 1700 anos depois do fim da democracia ateniense, estava preocupado em desenhar instituições que resistissem às situações críticas oriundas da dinâmica social nos Discorsi (Machiavelli et al., 1996), ou em propor soluções para evitar ou resolver situações hipercríticas em $O$ Príncipe (Machiavelli e Rebhorn, 2003).

É importante notar que todas essas soluções propostas pelo pensamento político "clássico" são de natureza conservadora, no sentido de preservarem ou restaurarem a ordem pública diante de situações críticas.

Mas a filosofia está longe de encerrar todas as soluções propostas na Antiguidade e no Renascimento para crises que ameaçam 
a estabilidade do corpo social e político. Na prática, outras soluções foram tentadas. A mais célebre delas vem da Roma republicana e atende pelo terrível nome de "ditadura". Esse instituto romano constituía na nomeação de um ditador (dictator) para governar monocraticamente a república durante o período de crise aguda, a fim de restituir a normalidade. Theodor Mommsen interpreta esse recurso constitucional romano como uma maneira de, em um contexto republicano, resgatar o princípio monárquico e colocá-lo a serviço de um fim bem específico e delimitado (Mommsen, 1959).

De fato, o dictator romano no período republicano tinha suas competências bastante limitadas. Era um posto temporário, que deixaria de existir assim que a crise fosse debelada. E não era qualquer crise, mas somente condições agudas como invasão por tropas estrangeiras, guerra civil e catástrofes, como fome generalizada. O ditador nunca poderia se autonomear. Pelo contrário, ele necessariamente precisava ser nomeado por um ou dois cônsules - a etimologia da palavra indica "aquele que foi apontado", indigitado, obviamente por outrem. A função tinha prazo determinado, sendo que o titular era obrigado a abdicar assim que a crise fosse debelada - Cícero escreve que, com o passar do tempo, foi adotado o prazo máximo de seis meses.

Mas se Roma nos legou esse exemplo de legislação para dar conta de situações de exceção, ela também produziu os primeiros exemplos históricos de sua usurpação pelas mãos de Lúcio Cornélio Sulla (138-78 a.C) e, em seguida, de Júlio Cesar (100-44 a.C.). Sulla cometeu o ineditismo de nomear a si mesmo ditador, ainda que o tenha feito com o uso de um preposto. Mesmo assim, sua ditatura legitimava-se pela tarefa de restituir a constituição do Estado (Nicolet, 2004). Cesar foi mais longe, ao ser nomeado em 44 a.C, ditador vitalício.

É importante notar que a despeito da importância do instituto da ditadura na Roma republicana e do papel que ele teve na transformação daquele regime em império, pelas mãos de generais 
como Sulla, Cesar e outros que os seguiram, ele raramente foi tratado pela teoria política até o século XX. Isso em parte se deve ao fato de a democracia antiga ter sido extinta no século IV a.C e a república romana no século I a.C. De lá até o advento das revoluções, o regime monárquico foi absolutamente hegemônico no ocidente, com a exceção das poucas repúblicas renascentistas italianas e outras poucas cidades-estado europeias, como Genebra no começo da era moderna. Ora, o instituto da ditadura como solução de crise só faz sentido em um regime republicano, pois ele é, como dissemos, uma restituição temporária do poder monárquico em um contexto em que ele não mais existe.

Assim, torna-se mais compreensível notar a entrada do tema no âmbito da reflexão política a partir da Era das Revoluções, pois essas revoluções pariram regimes republicanos, alguns dos quais ao longo do século XIX e XX emprestaram o nome de democracia - termo que até meados dos novecentos era utilizado exclusivamente para denominar o regime de participação direta e igualitária da Atenas clássica.

O principal autor a tratar do tema foi Carl Schmitt, um brilhante filósofo político alemão que se converteu em ideólogo do nazismo. A partir do exemplo romano, Schmitt propõe uma distinção entre dois tipos de ditadura: a comissária e a soberana. A primeira corresponde ao exemplo da Roma republicana, no qual o ditador é indicado por autoridades públicas e tem objetivo e tempo de atuação limitados. A forma soberana tem como exemplos históricos a monarquia absoluta, da idade moderna, e os governos monocráticos pós-revolucionários modernos. Ela corresponde a uma total concentração de poderes na mão de um ditador vitalício (Schmitt et al., 2014).

Mas Schmitt capta uma diferença importante entre o que chama de ditadura soberana e as ditaduras de Sulla e Cesar. Os antigos nunca abandonaram totalmente a ideia de restauração como objetivo e justificativa última da exceção ditatorial, já a ditadura 
soberana moderna, pelo contrário, se anuncia como caminho para a sociedade futura.

Crítico acerbo do liberalismo de sua época, Schmitt via nessa corrente de pensamento uma fraqueza estrutural relacionada a sua incapacidade de pensar situações de exceção. Autores fundacionais do liberalismo constitucional, como Montesquieu e James Madison, padeceram da ilusão de criar um sistema político autossuficiente e autorregulado - freios e contrapesos - que eles imaginavam imunes a crises agudas (McCormick, 2004).

Também inimigo declarado do comunismo, o autor alemão reconhece que o conceito de ditadura do proletariado, de Marx, capta melhor a necessidade de mecanismos para lidar com situações de exceção. Na verdade, os comunistas concebiam essa ditadura como solução para a crise final do sistema capitalista. Ela é uma ditadura comissária, pois tem um objetivo explícito, que é a aniquilação das bases materiais da sociedade capitalista, e sua vigência se extingue tão logo essa tarefa seja cumprida (Marx, 2012 [1875]). Diferentemente das ditaduras comissárias da Roma antiga, contudo, a ditadura do proletariado não tem por objetivo restaurar as instituições, mas sim desarticulá-las, criando as bases de uma nova sociedade (McCormick, 2004). Aqui encontramos novamente o processo de mudança semântica introduzido pelo Iluminismo e pela Era das Revoluções, já comentado no tocante ao conceito de crise: ao secularizar a ideia de providência divina, o Iluminismo criou uma forte esperança em um futuro redentor trazido pelas ações dos homens. Essa expectativa de um futuro redentor, sem intervenção divina, passou a habitar o campo semântico de conceitos políticos como crise, revolução e até mesmo ditadura.

A análise feita por Schmitt é brilhante, mas a conclusão a que chega é catastrófica. Sentindo-se ameaçado pelo comunismo soviético - na sua visão, mais preparado para oferecer soluções para a enorme crise econômica, política e social da Alemanha do entreguerras - Schmitt opta por apoiar uma solução ditatorial que 
pudesse fazer frente à ameaça comunista: uma ditadura soberana nacionalista (nazismo), na qual a figura do führer - em alemão, "líder", "condutor" ou "guia" - é central.

\section{A Constituição e a exceção}

A Constituição Federal hoje em vigor no Brasil contém de fato institutos que visam a dar conta de situações excepcionais, contidos mormente eu seu Título V - Da Defesa do Estado e das Instituições Democráticas. De cara podemos constatar o caráter explicitamente restaurador na justificação desses institutos, que com efeito suspendem direitos e garantias básicas estabelecidos pela própria carta para tempos de normalidade.

Há dois dispositivos no Título $\mathrm{V}$ da Constituição, o Estado de Defesa e o Estado de Sítio. O primeiro é decretado pelo Presidente da República, ouvidos o Conselho da República e o Conselho de Defesa Nacional, e o segundo necessita de autorização do Congresso Nacional para sua decretação. O Estado de Defesa aplica-se a "locais restritos e determinados" e tem por finalidade reestabelecer "a ordem pública ou a paz social ameaçadas por grave e iminente instabilidade institucional ou atingidas por calamidades de grandes proporções na natureza" (art. 136). Já o Estado de Sítio claramente atende a um grau emergencial mais agudo, e deve somente ser decretado em casos de guerra com nações estrangeiras ou "comoção grave de repercussão nacional ou ocorrência de fatos que comprovem a ineficácia de medida tomada durante o estado de defesa".

O Estado de Sítio ainda tem o limite constitucional de 30 dias de vigor e só pode ser prorrogado pelo mesmo período, a não ser em caso de guerra (art.137). As garantias constitucionais suspensas devem ser enumeradas no ato de seu decreto (art.138). Ademais, o Congresso Nacional só poderá autorizar sua decretação por maioria absoluta. 
No que toca a relação entre os poderes, a Carta ainda declara que "o Congresso Nacional permanecerá em funcionamento até o término das medidas coercitivas". Por fim, a Mesa do Congresso Nacional ainda designará comissão de cinco de seus membros para "acompanhar e fiscalizar a execução das medidas referentes ao estado de defesa e ao estado de sítio” (art. 140).

Esse resumo curto, mas abrangente, das medidas de exceção contidas na Constituição Federal, deixa claro seu caráter comissário. Primeiro, pela limitação no tempo e nas competências dos poderes excepcionais conferidos ao chefe do Executivo e, segundo, por sua dependência ex ante e expost do Poder Legislativo, isto é, o Congresso Nacional, que detém o poder de nomeação (pelo menos no caso mais agudo do Estado de Sítio) e de supervisão das medidas.

\section{A crise da pandemia}

É curioso notar que epidemias não são nomeadas explicitamente como razão suficiente para a instituição de ditaduras comissárias na Roma republicana e nem para a decretação de Estado de Defesa na Carta constitucional brasileira. É claro que podemos argumentar que as consequências da pandemia da Covid-19 poderiam muito bem se aproximar das graves crises de abastecimento que acometiam a Roma na antiguidade e se encaixam na categoria mais geral de "as calamidades de grandes proporções na natureza", prevista em nossa Constituição.

De fato, como já citamos, a pandemia causou uma miríade de crises, inclusive colocando em risco o funcionamento do Estado. Ora, para além da imensa pressão sobre os serviços públicos de saúde, de assistência e de seguridade social, a pandemia e as medidas tomadas para combatê-la prejudicaram praticamente todos os serviços públicos prestados pelos entes estatais, sejam eles municipais, estaduais ou federais. Muitos foram de fato interrompidos e estão até esse momento inativos. Mas seu impacto potencial sobre o Poder 
Legislativo seria ainda maior, e isso devido à natureza própria desse poder tão fundamental para o regime democrático.

Para entender tal diferença, é preciso que atentemos para a estrutura comunicativa de cada poder. O Executivo, muitas vezes chamado de braço administrativo do Estado, funciona mormente por meio de ordens, isto é, comunicações de caráter imperativo transmitidas ao longo de sua estrutura hierárquica (Habermas, 1984). Já o Poder Legislativo obedece a uma lógica comunicacional deliberativa. Parlamentares discursam, negociam e constroem consensos em torno de argumentos de justificação para as decisóes tomadas coletivamente nas casas legislativas. Por mais que a Câmara e o Senado não sejam espaços radicalmente igualitários do ponto de vista do poder de intervenção de cada um de seus membros, o caráter deliberativo de suas atividades é inegável. É exatamente nessa injunção que residiu a maior ameaça da pandemia à democracia brasileira: enquanto as atividades do Executivo foram de fato prejudicadas, a prática da deliberação legislativa correu o risco de ser completamente inviabilizada.

Isso não se deu em uma injunção qualquer de nossa história política. O presidente Jair Bolsonaro é declarado admirador de regimes ditatoriais, já demonstrou várias vezes ter pouco apreço pelas instituições democráticas responsáveis por limitar o poder do Executivo, especialmente o Congresso e o Supremo Tribunal Federal, que têm entre suas funções manter os atos do Poder Executivo no âmbito da legalidade e da constitucionalidade. Como mostrou estudo do Observatório do Legislativo Brasileiro, Bolsonaro é recordista na edição de decretos executivos, ${ }^{5}$ a tal ponto que o presidente da Câmara dos Deputados, Rodrigo Maia, o acusou publicamente de tentar "governar por decreto".

5 Disponível em: https://olb.org.br/o-que-a-guerra-de-decretos-diz-sobre-a-relacaoentre-congresso-e-executivo/

6 Disponível em: https://www.metropoles.com/brasil/politica-brasil/rodrigo-maia-ele-bolsonaro-queria-governar-por-decreto 
A pandemia abriu uma janela de oportunidade para o presidente expandir seus poderes sem sequer ter que apelar para medidas de exceção previstas na Constituição. Se as duas casas do legislativo federal tivessem suas atividades paralisadas, a responsabilidade de conduzir o país por esse longo período da pandemia restaria concentrada nas mãos do Executivo federal. Ou seja, o chefe do Executivo seria transformado em uma espécie de ditador de fato. Não precisamos recorrer ao exemplo da triste transição da república romana para o regime autocrático do império para aprender que o "poder de fato" tem uma capacidade enorme de se investir de aparências de legitimidade. ${ }^{7}$

O Congresso Remoto, seja por sua eficácia ou pela celeridade como foi implantado, fechou rapidamente tal janela, restituindo em grande medida a normalidade da relação entre poderes. A soberania popular, representada em sua pluralidade pelo legislativo, foi resguardada, e com ela a produção de medidas necessárias ao combate da pandemia, o funcionamento dos partidos, o controle das atividades do Executivo e a continuidade do debate público acerca das questôes mais importantes para o país. Esse último é um papel muito importante, porém pouco comentado pela literatura. A atividade parlamentar não é só deliberativa em seu funcionamento interno estrito, parlamentares funcionam também como correias de transmissão entre o Estado e a sociedade civil, servindo de fonte de informação e de mobilização do debate público nos meios de comunicação, associações e demais espaços públicos. Com o Congresso Remoto, essa importante função foi preservada.

Olhando retrospectivamente para as soluções pensadas pelas gerações que nos precederam para a crise em um contexto repu-

7 Os imperadores romanos frequentemente se investiam de títulos republicanos como princeps senatus, consul e pontifex maximus. Augusto, o primeiro deles, definia seu poder como puramente republicano e nunca assumiu o papel de monarca. Foi somente no século III d.C. que os imperadores romanos se assumiram plenamente como monarcas. 
blicano, vemos que a tecnologia computacional, hoje em dia tão detratada pelas consequências nefastas das redes sociais na política, pode também ter um papel fundamental na preservação das instituições, tornando possível que atividades essenciais sejam restauradas antes mesmo que forças políticas reclamem soluções excepcionais para a crise.

Certamente, o Congresso Remoto também pode ser visto como uma medida de exceção de caráter comissário, pois reduz a atividade parlamentar a seu essencial, descartando, por exemplo, o trabalho das comissões, as sessões plenárias, o acesso das pessoas aos plenários e gabinetes etc., inclusive concentrando mais poder nas mãos dos presidentes das Casas. No entanto, esse é um preço razoável a se pagar perante o benefício da não interrupção da atividade legislativa propiciada por ele, com todas as consequências positivas que ela acarreta. Como boa medida prudencial, o Congresso Remoto traz muito mais benefícios do que perdas.

A democracia nasceu direta na Antiguidade, tornou-se representativa ao longo do século XIX e agora ganha elementos virtuais. Esse desenvolvimento tem tudo a ver com as possibilidades abertas pelo avanço técnico e científico das sociedades humanas. Fato é que, ser por um lado temos consequências ruins como à intensificação de extremismos, a circulação de fake news e a operação de robôs nas redes sociais, temos também iniciativas como o Congresso Remoto, que são capazes de ter um enorme impacto sobre todo o sistema político. 


\section{Referências}

Aristotle. "Politics". In Everson, Stephen (ed.). The Politics and the Constitution of Athens. Cambridge, New York: Cambridge University Press. 1996

Habermas, Jürgen. The theory of communicative action. Boston: Beacon Press, 1984.

Koselleck, Reinhart e Richter, Michaela. "Crisis", Journal of the History of Ideas, v. 67, n. 2, p. 357-400, 2006.

Lovejoy, Arthur O. e Boas, George. Primitivism and related ideas in antiquity. Baltimore and London: John Hopkins University Press, 1935.

Machiavelli, Niccolò et al. Discourses on Livy. Chicago: University of Chicago Press, 1996.

Machiavelli, Niccolò e Rebhorn, Wayne A. The prince and other writings. New York: Barnes \& Noble Classics, 2003.

Marx, Karl. Critica do Programa de Gotha. São Paulo: Boitempo, 2012[1875].

Mccormick, John P. "From Constitutional Technique to Caesarist Ploy: Carl Schmitt on Dictatorship, Liberalism, and Emergency Powers". In Baehr, Peter e Richter, Melvin (ed.).Dictatorship in history and theory: Bonapartism, Caesarism, and totalitarianism. Washington, D.C./Cambridge, UK; New York; German Historical Institute; Cambridge University Press, p. 197-219, 2004.

Mommsen, Theodor. The history of Rome. New York: Philosophical Library, 1959.

Nicolet, Claude. "Dictatorship in Rome”. In Baehr, Peter e Richter, Melvin (eds.). Dictatorship in history and theory: Bonapartism, Caesarism, and totalitarianism. Washington, D.C. Cambridge, UK; New York, German Historical Institute; Cambridge University Press, p. 263-78, 2004.

Plato e Jowett, Benjamin. The republic. Mineola, N.Y.: Dover Publications, 2000.

Pocock, John G. A. The Machiavellian moment: Florentine political thought and the Atlantic republican tradition. Princeton, N.J.: Princeton University Press, 1975.

Schmitt, Carl et al. Dictatorship: from the origin of the modern concept of sovereignty to proletarian class struggle. Cambridge, UK; Malden, MA: Polity Press, 2014. 